\title{
Evaluation of the Photosonolysis Process Efficacy for the Removal of Anionic Surfactant Linear Alkyl Benzene Sulfonate from Aqueous Solutions
}

\author{
Tahereh Razavi ${ }^{1}$, Abdolmajid Fadaei $^{\mathrm{i}^{*}}$, Mehraban Sadeghi ${ }^{3}$, Morteza Sedehi ${ }^{4}$ \\ 1 Students' Research Committe, Research center, Shahrekord University of Medical Sciences, Shahrekord, Iran \\ 2,3 Department of Environmental Health Engineering, School of Public Health, Shahrekord University of Medical \\ Sciences, Shahrekord , Iran \\ ${ }^{4}$ Department of Medical Epidemiology and Biostatistics, School of Public Health, Shahrekord University of \\ Medical Science, Shahrekord, Iran \\ * Corresponding author's e-mail: ali2fadae@yahoo.com
}

\begin{abstract}
In this study, the experiments on the sulfonate linear alkylbenzene (LAS) solution were performed using the methylene blue active substances (MBAS) method. The effectiveness of the sonochemical and photochemical reactors for LAS degradation was evaluated with an emphasis on the effect of the contact time, $\mathrm{pH}$ values, type of process and initial concentrations. The experiments were carried out at the initial concentrations of $0.5 \mathrm{mg} / \mathrm{L}, 14.00 \mathrm{mg} / \mathrm{L}$ and $21.00 \mathrm{mg} / \mathrm{L}$, the contact time of 8,16 , and 24 minutes, $\mathrm{pH}$ of 3,7 , and 11 , the ultrasonic frequency of $42 \mathrm{kHz}$, the acoustic power value of $160 \mathrm{~W}$, an ultraviolet lamp with $150 \mathrm{~W}$ power and the wavelength of $254 \mathrm{~nm}$. This study showed that the LAS degradation was increased along with the contact time. In addition, at alkaline $\mathrm{pH}$, the removal efficiency increased as well. Overall, the results obtained from this research demonstrated that by themselves, both the sonochemical and photochemical reactors may not be useful for completely reducing the complex wastewaters with high surfactant loads, but the succession of the UV/US process has a significant effect on the removal of anionic detergents. These findings demonstrated the removal efficiency under alkaline conditions and the contact time of 24 minutes was equal to 96.97 percent.
\end{abstract}

Keywords: LAS, sonochemical, photochemical

\section{INTRODUCTION}

Considering the prevalent use of surfactants in agriculture and households, the water pollution has increased in recent years [1]. The commonly used active components include surfactants, hydrophilic molecules, and hydrophobic tails of soap and detergent formulations. These molecules generally assemble at the interference of the aqueous medium with other phases (e.g., air) $[2,3]$. Accordingly, the anionic surfactants can be classified into cationic, nonionic, amphoteric, and anionic groups [4]. Overall, the anionic surfactants constitute two-thirds of total ionic surfactants [5].
Due to such problems as the ability to break down long-term storage at ambient foaming in wastewater and rivers, ABS was replaced with sulfonate linear alkylbenzene (LAS) in 1960 [6, 7]. The presence of detergents in the water causes numerous environmental problems, including the aggregation of foam on the water surface and preventing oxygenation of the water, producing unpleasant taste and odor, disorders in coagulation and flocculation, and biological dysfunction in aquatic environments [8,9]. LAS contains sulfate and has different properties, as shown in Table 1; therefore, if present in water resources, it rapidly promotes the growth of aquatic plants and produces negative ions. After decomposition 
of aquatic plants, dissolved oxygen for sewage oxidation and aquatic life is reduced $[10,11]$. The EPA standards of Iran pertaining to the effluent discharge of detergent to surface water $(1.5 \mathrm{mg} / \mathrm{l})$ as well as drain wells and irrigation and agriculture $(0.5 \mathrm{mg} /) 1$ were levied [12]. In 1989, EPA recommended the second concentration of foaming agents to $0.5 \mathrm{mg} / \mathrm{l}$ in drinking water [13]. Advanced oxidation technologies have been used effectively in recent years for elimination of toxic compounds, particularly in wastewater treatment plants, with chemical stability and low biodegradation $[14,15]$. Hydroxyl free radicals, which can convert organic compounds into minerals, have high oxidation power and are produced by pollutant removal using oxidation technologies [16]. Unstable and extremely reactive hydroxyl radicals are produced through chemical reactions or photochemical production in place. These free radicals are quickly-acting powerful oxidizing organic molecules, removing and a hydrogen atom from the organic matter [17]. Advanced oxidation process involves $\mathrm{H}_{2} \mathrm{O}_{2}, \mathrm{UV}$, US, and $\mathrm{O}_{3}$ [18]. On the whole, it must be admitted that the correct selection and operation of the UV system is an economically feasible option compared to other methods of water purification [19]. Recently, the US (ultrasonic) has been used to remove the surfactant from wastewater [20, 21]. Ultrasonic process (using ultrasound) is one of the most effective technologies known for the decomposition of organic pollutants. The important advantages of US compared to other purification technologies are: safety, cleanliness and maintenance of energy without generating secondary pollutants [22, 23]. The benefits of UV and US are lack of secondary waste products and need for the addition of chemicals as well as being easy to set up [24]. According to the studies conducted so far, no report on the LAS removal using a combination of UV/US have been reported. This study aimed to provide a method for removing pollutants without deteriorating the environmental safety of LAS, to determine the association of retention time and $\mathrm{pH}$ with efficient LAS removal, and to determine the effect of subsequent UV/US for anionic detergent removal.

\section{MATERIALS AND METHODS}

Profiling method. In the assay, a substance which reacts with methylene blue and is responsive to compounds with a hydrophobic and anionic group is usually used. Therefore, in the environmental samples, the assay may be limited due to analytical interference; this method has sensitivity of nearly $0.02 \mathrm{mg} / \mathrm{L}$. For the analysis of LAS, an improved strategy is suggested dependent on high-performance liquid chromatography and methylene blue reactivity.

Methylene blue is transferred from an aqueous solution into an organic liquid by methylene blue active substances (MBAS) in equilibration. This occurs due to the formation of ion pairs by the methylene blue cation and MBAS anion. A measure of MBAS in the organic phase is the intensity of the produced blue color. Overall, this method is relatively accurate and simple and is applicable for the MBAS levels as low as $0.025 \mathrm{mg} / \mathrm{L}$. It is characterized by 3 sequential extractions from the acid aqueous medium of methylene blue overload in chloroform, aqueous backwash, and measurement of blue color in chloroform via $652 \mathrm{~nm}$ spectrophotometry.

Apparatus and procedures. In this study, a spectrophotometer was used at $652 \mathrm{~nm}$, providing a $1-\mathrm{cm}$ light path. Separatory funnels $(500 \mathrm{~mL}$, USA), preferably with inert TFE stopcocks and stoppers (250 power) were also applied. Moreover, for sonochemical experiments, a sonochemical reactor (Basin-Batch; Fig. 1) was employed, operating at $160 \mathrm{~W}$ and $42 \mathrm{kHz}$ (Table 2). A generator, connected to the transducer, was used for

Table 1. Properties of LAS

\begin{tabular}{|c|c|c|c|}
\hline LAS & Structure & $\lambda_{\text {max }}, \mathrm{nm}$ & $\mathrm{MW}, \mathrm{Gr} / \mathrm{cm}^{3}$ \\
\hline & $\left.\mathrm{H}_{3} \mathrm{C}-\left(\mathrm{CH}_{2}\right) x-\mathrm{CH}_{2}\right) y-\mathrm{CH}_{3}$ & & \\
\hline $\begin{array}{l}\text { Linear alkyl } \\
\text { benzene sulfonat }\end{array}$ & & 652 & 0.8628 \\
\hline
\end{tabular}




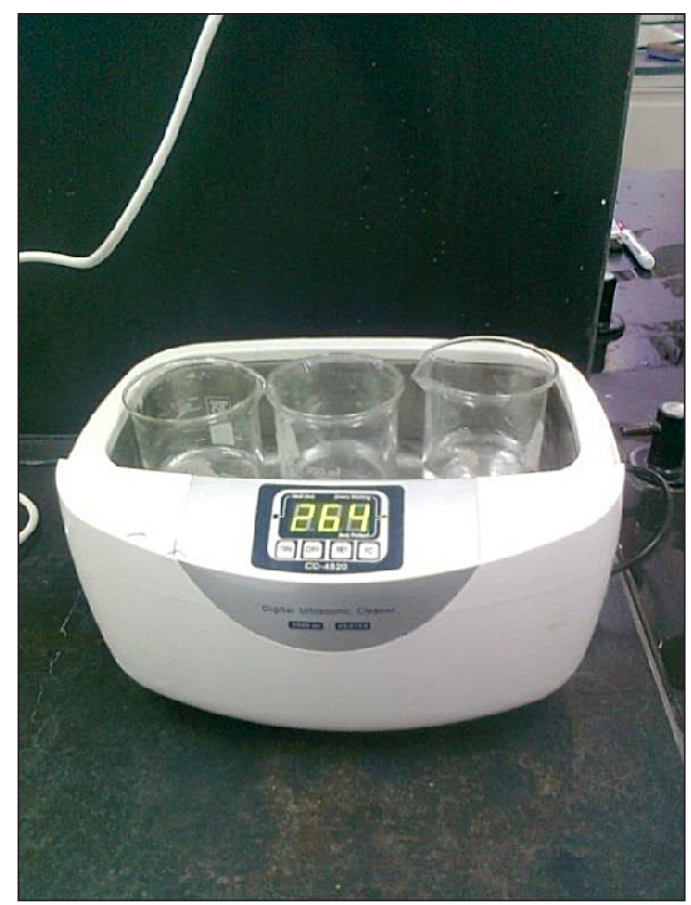

Fig. 1. Sonochemical reactor for LAS degradation

adjusting frequency and power. For all reactions, a stainless steel vessel, immersed in a water bath, was used. A detergent aqueous solution $(100 \mathrm{~mL})$ was prepared every day and exposed in the sonochemical reactor. Sonication was performed with sound waves from the bottom of the reactor.

UV reactor: an ultra violet lamp operating in power value of $150 \mathrm{~W}$ and with a wavelength of $254 \mathrm{~nm}$ and medium pressure that produced a temperature of about $80^{\circ} \mathrm{C}$. The pilot plant used in this study was a 5-liter buccal. It was chosen due to the heat generated by the lamp (buccal plays the role of cooling). In order to prevent the UV radiation around the buccal, it was covered with aluminum. In order to adjust $\mathrm{pH}$ of $\mathrm{HCl}$ and $\mathrm{NaOH}$, a normal $\mathrm{pH}$ meter was used.

Materials. A stock solution of LAS was used in the experiments, and $1.00 \mathrm{~g}$ of LAS was weighed on a $100 \%$ active basis as the reference material. The stock LAS solution $(10 \mathrm{~mL})$ was

Table 2. Characteristics of the sonochemical reactor used in the experiments

\begin{tabular}{|l|c|}
\hline \multicolumn{1}{|c|}{ Parameters } & Characteristics \\
\hline Frequency & $42 \mathrm{KHZ}$ \\
\hline Power & $160 \mathrm{~W}$ \\
\hline Reactor type & Basin \\
\hline Flow type & Batch \\
\hline Dimensions & $\mathrm{L}=264 \mathrm{~mm}, \mathrm{~W}=164 \mathrm{~mm}, \mathrm{H}=80 \mathrm{~mm}$ \\
\hline Water depth & $2.5 \mathrm{~L}$ \\
\hline
\end{tabular}

diluted in $1000 \mathrm{~mL}$ of water. Phenolphthalein was used as an indicator in alcohol. In addition, sulfuric acid (1 and $6 \mathrm{~N}$ ), chloroform, and sodium hydroxide $(\mathrm{NaOH}, 1 \mathrm{~N})$ were used. In the experiments, methylene blue reagent $(100 \mathrm{mg})$ was dissolved in water $(100 \mathrm{~mL})$. Afterwards, the solution $(30 \mathrm{~mL})$ was added to a flask $(1000 \mathrm{~mL})$, and water $(500 \mathrm{~mL})$, sulfuric acid $(6 \mathrm{~N}, 41 \mathrm{~mL})$, sodium phosphate, and monobasic monohydrate $(50 \mathrm{~g})$ were added. A washing solution was also used in the experiments. Sulfuric acid (6 N, $41 \mathrm{~mL})$ was first added to water $(500 \mathrm{~mL})$ in the flask. After adding $\mathrm{NaH}_{2} \mathrm{PO}_{4} \cdot \mathrm{H}_{2} \mathrm{O}(50 \mathrm{~g})$, it was shaken until being dissolved; finally, it was diluted to $1000 \mathrm{~mL}$. In addition, hydrogen peroxide and methanol were used. Glass wool, pre-extracted with $\mathrm{CHCl}_{3}$, was also used for removing the interferences. Water, MBAS-free water, and reagent-grade water were used for preparing all reagents and dilutions.

A series of reparatory funnels of standard LAS solution $(0.5,5,15,20$, and $25.00 \mathrm{~mL})$ were prepared for the calibration curve. Water was added to the reparatory funnel to reach a total volume of $100 \mathrm{~mL}$. The calibration curve of absorbance was plotted against LAS micrograms, showing LAS molecular weight. Finally, a sample volume with respect to the MBAS level was used for direct analysis (Table 2).

Extraction. The sample was first added to a reparatory funnel. Using phenolphthalein and drop-wise addition of $\mathrm{NaOH}(1 \mathrm{~N})$, the alkaline indicator was prepared. The pink color was produced by drop-wise addition of $1 \mathrm{~N}$ sulfuric acid. Following that, the methylene blue reagent $(25 \mathrm{~mL})$ and $\mathrm{CHCl}_{3}(10 \mathrm{~mL})$ were added. After shaking the funnel vigorously for 30 seconds, phase separation was performed. A magnetic stirring bar was alternatively placed in the reparatory funnel. After putting the funnel on a magnetic mixer, the stirring speed was modified for a rocking motion. For breaking persistent emulsions, a low volume of isopropyl alcohol was used. The duration of required phase separation was longer in some samples.

After gently swirling the sample, it was allowed to settle before the drainage of the $\mathrm{CHCl}_{3}$ layer. A second reparatory funnel was used to remove the $\mathrm{CHCl}_{3}$ layer. Then, a small amount of $\mathrm{CHCl}_{3}$ was used to wash the delivery tube of the first funnel. Extraction was repeated 2 more times with $10 \mathrm{~mL}$ of $\mathrm{CHCl}_{3}$. As soon as the blue color became faint in the water phase, it was discarded; 
then, a smaller amount of sample was used to repeat the process.

In the second reparatory funnel, the $\mathrm{CHCl}_{3}$ extracts were mixed. After adding the washing solution $(50 \mathrm{~mL})$, the mixture was shaken vigorously for 30 seconds. No emulsion was formed at this stage, and it was allowed to settle and swirl. The $\mathrm{CHCl}_{3}$ layer was removed with a funnel of glass wool and added to a volumetric flask $(100 \mathrm{~mL})$. Extraction of the washing solution was done twice using $10 \mathrm{~mL}$ of $\mathrm{CHCl}_{3}$; the solution was then poured in the flask of glass wool. Both the funnel and glass wool were washed with $\mathrm{CHCl}_{3}$.

After collecting the washings in the volumetric flask, they were diluted to mark with $\mathrm{CHCl}_{3}$ and then mixed. Absorbance was measured at $562 \mathrm{~nm}$ against a $\mathrm{CHCl}_{3}$ blank. The standard methods for water and wastewater examination were applied for all the analyses [25].

Statistical analysis. The Taguchi design was used to examine the capacity of a sonochemical reactor in LAS degradation. In order to determine the optimal conditions for the LAS removal from aqueous solutions, the Taguchi experimental design was applied. Signal-to-noise $(\mathrm{S} / \mathrm{N})$ ratio and ANOVA were performed to analyze the results Taguchi software and SPSS 16 were used for data analysis.

\section{RESULTS AND DISCUSSION}

Photodegradation and sonodegradation of LAS were applied for 8,16 , and 24 minutes at $\mathrm{pH}$ of 3,7 , and 11. LAS sonodegradation was carried out at initial levels of $0.5,14$, and $21 \mathrm{mg} / \mathrm{L}$ (acoustic frequency, $42 \mathrm{kHz}$ ). Photodegradation of LAS was performed with power of $150 \mathrm{~W}$ at wavelength of $254 \mathrm{~nm}$. In addition, the sequential UV/US was also performed with these concentrations. Minitab version 16 was used for evaluating

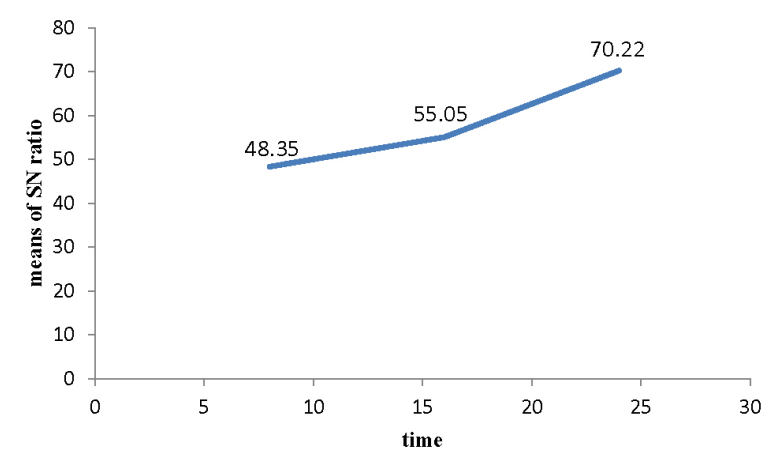

Fig. 2. Effect of contact time in US reactor the effect of each parameter on the optimization criteria. The $\mathrm{S} / \mathrm{N}$ ratio was measured with the Taguchi method to determine the deviation of quality characteristic from the desired level; the $\mathrm{S} / \mathrm{N}$ ratio varies with respect to the characteristics.

\section{Effects of sonication and irradiation time}

For evaluating the influence of irradiation time and sonication on the rate of LAS degradation, sonication and irradiation of aqueous LAS were carried out in 3 intervals. Substantial LAS degradation was expected after 24 minutes. On the basis of the findings, the degradation efficiency increased as time advanced (Fig. 2-4) and the removal percentage increased with time $(\mathrm{P}<0.05)$. This finding may be attributed to the longer exposure time between the LAS solution and acoustic cavitation, as the time of sonication and UV irradiation increases [26, 27]. Dehghani et al. have reported similar findings on sonication time [28]. Additionally, the findings of these studies were consistent regarding the irradiation time. As indicated by Dehghani et al., the removal efficiency increased along with the sonication time; because in this time (maximum time), the audio bubbles were increased. Therefore, the contact between LAS and bubbles was increased, so the degradation was increased [29]. In a study by Kim et al. on alachlor with UV irradiation (at 1 to 6 hours), an increase in the degradation efficiency was reported by increasing the irradiation time [30].

\section{Effect of $\mathrm{pH}$}

The experiments were conducted at $\mathrm{pH}$ of 3, 7 and 11. The efficiency of anionic detergent (LAS) removal under alkaline conditions was better than that under acidic conditions, as shown in Figure 5. The relationship between the $\mathrm{pH}$ and

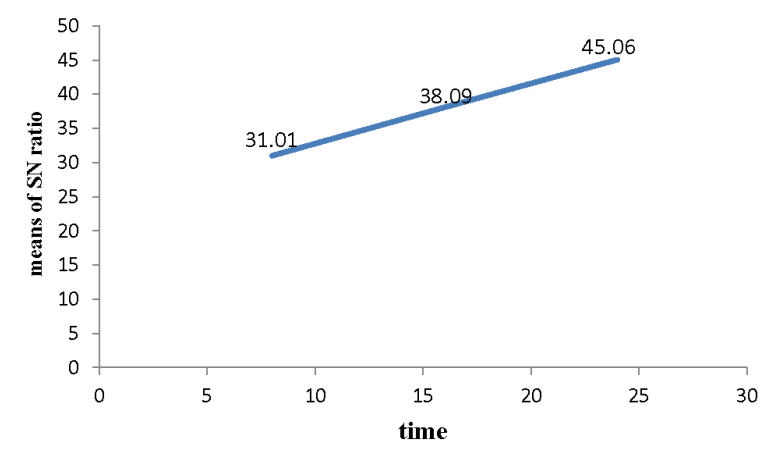

Fig. 3. Effect of contact time in UV reactor 


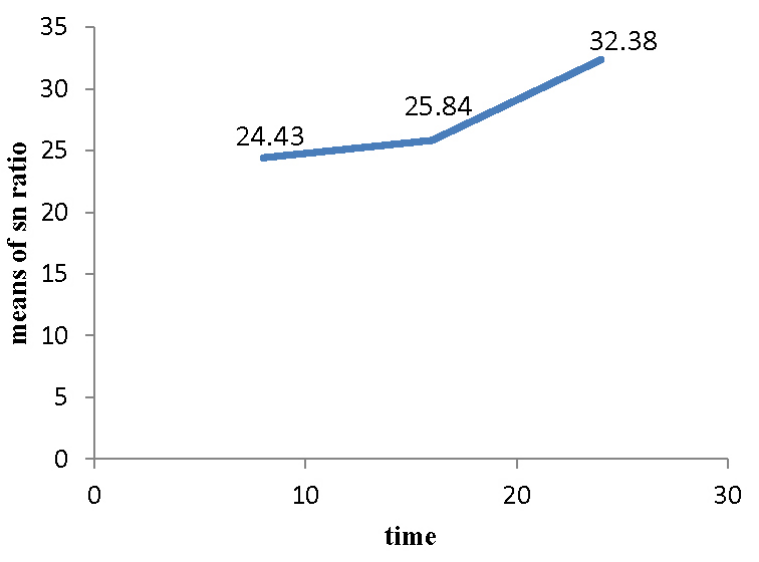

Fig. 4. Effect of contact time in UV/US reactor

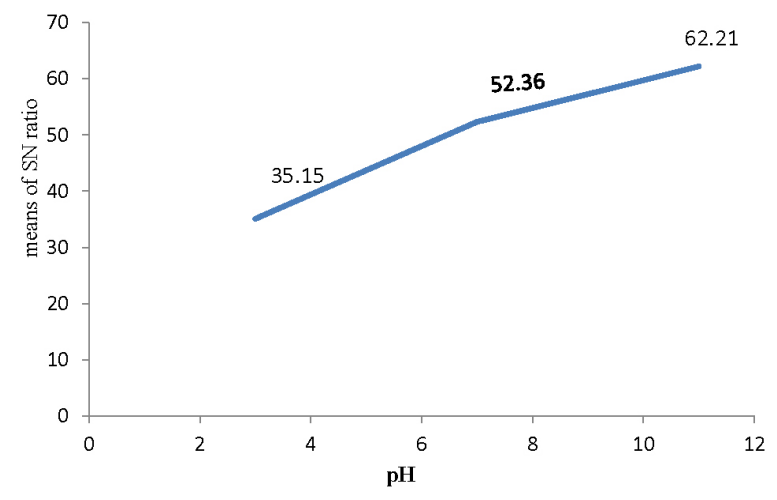

Fig. 5. Effect of $\mathrm{pH}$ in UV/US reactor

the percentage of the detergent removal is significant $(\mathrm{P}<0.05)$, as shown in Figure $5(31,32)$. In fact, the hydroxyl radicals increased along with $\mathrm{pH}$, and then the LAS degradation was increased as well [33] (Liu et Al. [33], Addams et al. [32].

\section{Effect of type of process and synergetic UV/US}

The experiments showed that insertion of soluble anionic detergents, exposed to the UV radiation, had little effect on the surfactant decomposition. The removal efficiency of the

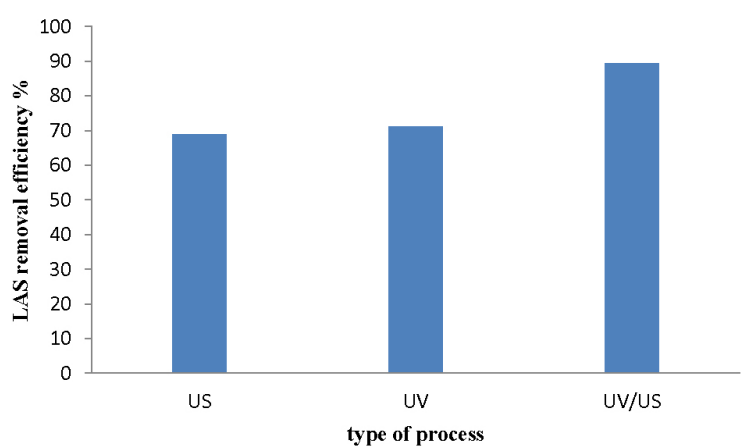

Fig. 6. The removal efficiency of UV, US and UV/US processes

sequential process (UV/US) is higher than in UV process and US process, as shown in Figure 6. Nanzai et al. in 2009 used a sonochemical reactor for the LAS degradation from the wastewater effluent and concluded that the sonochemical reactor alone may not be useful for reducing the high surfactant load from completely complex wastewater [34, 35]. According to the research, the efficacy of sonophotolysis is higher than sonochemical reactor and photochemical reactor. When both processes (UV, US) are used together, more hydroxyl radicals are generated. Thus, the decomposition and oxidation rate increases [36]. Another reason for this matter is the synergetic impact of the three mechanisms, including the degradation of optical, ultrasonic decomposition and oxidation by ozone. The UV light propagation in air produced ozone from oxygen. Therefore, the UV light propagation in the air at the top of reactor produced ozone and its transfer to the solution and increased the decomposition [36]. The removal percentage of each of the processes (UV, US, UV/US) is presented in table 3. In this table, the UV process is shown with level 1 , the US process is demonstrated with level 2 and the UV/US process is presented with level 3.

Table 3. Experimental variables, their result in one of the concentrations ( $14 \mathrm{mg} / \mathrm{L})$ of LAS

\begin{tabular}{|c|c|c|c|c|c|c|c|c|}
\hline \multirow{2}{*}{$\begin{array}{c}\text { Experiment } \\
\text { number }\end{array}$} & \multicolumn{4}{|c|}{ Variables } & \multicolumn{4}{c|}{ LAS removal efficiency, \% } \\
\cline { 2 - 9 } & UV & US & UV/US & $\mathrm{pH}$ & Time, min & UV & US & UV/US \\
\hline 1 & 1 & 2 & 3 & 3 & 8 & 38.33 & 21.9 & 45.14 \\
\hline 2 & 1 & 2 & 3 & 3 & 16 & 50.00 & 36.23 & 56.35 \\
\hline 3 & 1 & 2 & 3 & 3 & 24 & 55.17 & 47.7 & 65.00 \\
\hline 4 & 1 & 2 & 3 & 7 & 8 & 40.82 & 36.80 & 66.14 \\
\hline 5 & 1 & 2 & 3 & 7 & 16 & 49.12 & 45.22 & 70.24 \\
\hline 6 & 1 & 2 & 3 & 7 & 24 & 57.32 & 57.12 & 79.28 \\
\hline 7 & 1 & 2 & 3 & 11 & 8 & 52.23 & 51.3 & 66.71 \\
\hline 8 & 1 & 2 & 3 & 11 & 16 & 65.91 & 62.06 & 87.14 \\
\hline 9 & 1 & 2 & 3 & 11 & 24 & 71.19 & 68.96 & 89.35 \\
\hline
\end{tabular}


The potential of sonochemical and photochemical reactors in LAS degradation and the role of $\mathrm{pH}$ and contact time were studied. On the basis of the experiments, contact time is an important parameter for the LAS degradation. This study also showed that the overall treatment efficiency improves as $\mathrm{pH}$ increases.

\section{CONCLUSION}

The findings showed that sonochemical and photochemical reactors may not be useful for reducing high surfactant loads from completely complex wastewater, although the sequential UV/US process has a major impact on the removal of anionic detergent; the removal efficiency under alkaline conditions and contact time of 24 minutes was equal to $96.97 \%$.

\section{REFERENCES}

1. Ying G. 2006. Fate Behavior and effect of surfactants and their degradation products in the environment. Environ. Int., 32, 417.

2. Venhuis S.H., Mehravar M. 2004. Health effects, environmental impacts, and photochemical degradation of selected surfactant in water. Int J. Photoenergy., 6(3), 115.

3. Urum K,Pekdemir T. 2004.Evaluation of biosurfactant for crude oil contaminated soil washing. Chemosphere, 57(9), 1139.

4. Adak A., Bondyopadhayay M., Pal A. 2005.Removal of anionic surfactant from wastewater by alumina-a case study. Colloids Surf A: Physicochem. Eng. Asp., 254(1-3), 165.

5. Gupta S., Pal A., Ghosh P. 2003. Performance of waste activated carbon as a low cost adsorbent for the removal of anionic surfactant from aquatic environment. Journal of Environmental Science and Health, Part A, 38(2), 381-397.

6. Houas A., Lachhe H., Ksibi M., Elaloui E., Guillard C., Herrmann J.M. 2001. Photocatalytic degradation pathway of methylene blue in water. Appl. Catal. B: Environ. A, 31(2), 145.

7. Savas K.A., Onder E., 2006. Removal of linear alkylbenzene sulfonate from a model solution by continuous electrochemical oxidation. Desalination, 197(1-3), 262.

8. AkariT., Maki K., Yoshinori K. 2017. Removal of anionic surfactant sodium dodecyl benzene sulfonate (SDBS) from wastewaters by zero-valent iron (ZVI): predominant removal mechanism for effective SDBS removal. Environ. Sci. Poll. Res., 24(9), 8087.

9. Hossein F., Malekzadeh F., Amirmozafari N., Ghae$\min$ N. 2007. Biodegredation of anionic surfactants by isolated bacteria from activated sludge. Int. J. Environ. Sci. Technol., 4(1), 127.

10. Ghaderpoori M., Dehghani M.H. 2016. Investigating the removal of linear alkyl benzene sulfonate from aqueous solution by ultraviolet irradiation and hydrogen peroxide process. Desalin. Water Treat., 57(32), 15208.

11. Gonzalez E., Broun A., 1998. Fate and distribution linear alkyl benzene sulfonates in the littoral environment. Environ. Sci. Technol., 32(11), 1636.

12. Blasco J., Gonzalez Mazo E.,Sarasquete C. 2008. Linear Alkyl benzene sulfonate (LAS) and bioaccumulation of heavy metals $(\mathrm{Cu}, \mathrm{Pb})$ in Ruditapesphilipiharum. Toxicol Environ Chem.,71, 447.

13. Weinberger W., Powers T.J. 1964. The detergents and water quality standards. J. Am. Oil Chem. Soc., 41(11), 736.

14. Jardak K., Drogui P., Daghrir R. 2016. Surfactants in aquatic and terrestrial environment: Occurrence, behavior, and treatment processes. Environ. Sci. Pollut. Res., 23(4), 3195.

15. Abdollahi Y., Abdullah A.H., Zainal Z., Yusof N.A. 2012. Degradation of $\mathrm{m}$-cresol with $\mathrm{Mn}$ doped $\mathrm{ZnO}$ nanoparticles under visible light irradiation. Fresen. Environ. Bull., 21, 256.

16. Oller I., Malato S., Sanchez J. 2011. Combination of advanced oxidation processes and biological treatment for wastewater decontamination, a review. Sci. Total Environ., 409(20), 4141.

17. Momani F., Touraud E., Domas D.,Russay R., Tomas O.2002.Biodegradability enhancement of textile dyes and textile wastewater by UV photolysis. J. Photochem. Photobiol. Chem.,153(1-3), 191.

18. Ledakowicz S.,Solecka M., Zylla, R. 2001. Biodegradation, decolourisation and detoxification of textile wastewater enhanced by advanced oxidation processes. J. Biotechnol., 89(2-3), 175.

19. Vaezi F., Nabizadeh F., Mesdaghinia A., Rahimzadeh H. 2007. Evaluating of the disinfection and water quality effects on UV application in the primary stage of water treatment. Iran J. Public Health, 36(2), 12.

20. Belgiornoa V., Rizoo L., Fatta D., Rocca C., Lofrano G., Nikolaou A., Naddeo V., Merice S. 2007. Review on endocrine disrupting-emerging compounds in urban wastewater: occurrence and removal by photocatalysis and ultrasonic irradiation for wastewater reuse. Desalination, 215(1-3), 166.

21. Gallipoli A., Braguglia C. 2012. High-frequency ultrasound treatment of sludge: Combined effect of surfactants removal and flock disintegration, 
Ultrason. Sonochem., 19(4), 864.

22. Nikfar E., Dehghani M.H, Mahvi A.H, Rastkari N., Asif M., Tyagi Inderjeet, Agarwal Shipi, Gupta Vinod Kumar. 2016.Removal of Bisphenol A from aqueous solutions using ultrasonic waves and hydrogen peroxide. J. Mol. Liq., 213, 332.

23. Weavers L.K., Pee G.Y., Frim J.A., Yang L. Rathman J.F., 2005.Ultrasonic destruction of surfactants: application to industrial wastewaters. J. Water Environ. Res., 77(3), 259.

24. Lifka J., Ondruschka B., Hofmann J., 2003. The use of ultrasound for the degradation of pollutants in water, aquasonolysis - a review. Eng. Life Sci., 3(6), 253.

25. APHA. 2005. Standard Methods for the Examination of Water and Wastewater, 19th ed. American Public Health Association. Water Environment Federation Washington, DC.

26. Ashokkumar M., Niblett T., Tantiongco L., Grieser F. 2003. Sonochemical degradation of sodium dodecyl benzene sulfonate in aqueous solutions. J. Chemstry, 56(10), 1045.

27. Yim B., Okuno H., Nagata Y., Nishimura R., Maeda Y. 2002. Sonolysis of surfactants in aqueous solutions: an accumulation of solute in the interfacial region of the cavitation bubbles, Ultrason. Sonochem, 9(4), 209.

28. Dehghani M.H., Najafpoor A., Azam K. 2010. Using sonochemical reactor for degradation of LAS from effluent of wastewater treatment plant. Desalination, 250(1), 82.
29. Dehghani M.H., Nasseri S., Ghaderpoori M., Mahvi A.H, Nabizadeh R., 2011. Investigation the efficiency of $\mathrm{UV} / \mathrm{H}_{2} \mathrm{O}_{2}$ process for removal of LAS in aqueous solutions. Iran J. Health \& Environ., 3, 411.

30. Kim M.S., Ryu C.S., Kim B.W. 2005.Effect of ferric ion added on photodegradation of alachlor in the presence of $\mathrm{TiO} 2$ and $\mathrm{UV}$ radiation, Water Res., 39(4), 525.

31. Panizza M., Barbucci A., Delucchi M., Carpanese M.P., Giuliano A., Cataldo-Hernandez M., Cerisola G., 2013. Electro-Fenton degradation of anionic surfactants. Sep. Purif. Technol., 118, 394.

32. Adams C.D, Kuzhikannil J.J., 2000. Effects of UV/ $\mathrm{H}_{2} \mathrm{O}_{2}$ preoxidation on the aerobic biodegradability of quaternary amine surfactants. Water Res., 34(2), 668-672.

33. Liu yn, jin D, LU X.P, Han P.F, 2008.Study on degradation of dimethoate solution in ultrasonic airloop reactor. Ultason.Sonochem., 15(5), 755.

34. Nanzai B., Okitsu, Takenaka N., Bandow H. 2009. Sonochemicaldegradation of alkylbenzene sulfonates and kinetics analysis with a langmuirlype mechanism. J. Phys. Chem., 113(9), 3735.

35. Ren Z., Luo Y., Shi D. 2013. Mechanism on the interaction between amino sulfonate amphoteric surfactant and sodium dodecyl benzene sulfonate in aqueous solution. Colloids Surf A Physicochem. Eng. Asp., 428, 18.

36. Fadaei A.M., Kargar M. 2013. Photocatalytic degradation of Chlorpyrifos in water using titanium dioxide and zinc oxide. Fresen. Environ. Bull, 22, 2442. 